\title{
FITOTECNIA
}

\section{ESTRESSE POR ALUMíniO EM GENÓTIPOS DE AVEIA PRETA EM CONDIÇÃO HIDROPÔNICA $\left(^{1}\right)$}

\author{
MARAISA CRESTANI $\left(\left(^{2,6 *}\right)\right.$; FERNANDO IRAJÁ FÉLIX DE CARVALHO $\left({ }^{3}\right)$; ANTONIO COSTA DE OLIVEIRA $\left({ }^{3}\right)$; \\ JOSÉ ANTONIO GONZALEZ DA SILVA $\left({ }^{4}\right)$; VELCI QUEIRÓZ DE SOUZA $\left({ }^{5}\right)$; ENRIQUE ALFREDO MOLITERNO \\ PARACHU $\left({ }^{3}\right)$; GUSTAVO DA SILVEIRA $\left({ }^{2,7}\right)$; GUILHERME RIBEIRO $\left({ }^{2,6}\right)$; HENRIQUE DE SOUZA LUCHE $\left({ }^{2,8}\right)$
}

\begin{abstract}
RESUMO
Um dos fatores abióticos que interferem fortemente no crescimento e desenvolvimento da aveia preta (Avena strigosa Schreb.) é o nível de alumínio (Al) livre presente na solução dos solos de elevada acidez, que, depois de absorvido, afeta células e organelas em nível morfológico, citogenético e fisiológico, prejudicando consequentemente, a produtividade das plantas. Neste sentido, genótipos de aveia preta foram submetidos ao estresse por alumínio em condições de hidroponia com o objetivo de determinar o caráter mais efetivo para a seleção de plântulas desta espécie em ambiente controlado. Além disto, teve como propósito caracterizar distintas constituições genéticas de aveia preta visando a composição de blocos de cruzamento e auxiliar na recomendação de genótipos em ambientes com elevada concentração deste elemento químico, além de estabelecer a concentração ideal de alumínio que possibilite melhor eficiência na detecção do nível de tolerância ao alumínio em condição hidropônica. O delineamento experimental adotado foi o completamente casualizado num esquema fatorial 5 x 10 (dose x genótipo), adotando o método de avaliação proposto por Camargo e Oliveira, em 1981, empregando cinco níveis de alumínio: 0, 5, 10, 20 e $40 \mathrm{mg} \mathrm{L}{ }^{-1}$, adicionados na fonte $\mathrm{Al}_{2}\left(\mathrm{SO}_{4}\right)_{3} \cdot 18 \mathrm{H}_{2} \mathrm{O}$. O caráter comprimento de raiz e as doses 10 e $20 \mathrm{mg} \mathrm{L}^{-1}$ de $\mathrm{Al}^{3+}$ proporcionaram a melhor diferenciação entre os genótipos em relação à tolerância ao alumínio. A cultivar de aveia preta IAPAR 61 evidenciou grande sensibilidade ao Al, ao contrário da PRETA COMUM e da EMBRAPA 140, que expressaram elevada tolerância à presença do elemento tóxico no ambiente de cultivo.
\end{abstract}

Palavras-chave: Avena strigosa Schreb.; solução nutritiva; caracteres de plântula, tolerância; sensibilidade.

(1) Recebido para publicação em 6 de maio de 2008 e aceito em 6 de fevereiro de 2009.

$\left(^{2}\right)$ Centro de Genômica e Fitomelhoramento - Faculdade de Agronomia "Eliseu Maciel" (FAEM) - Universidade Federal de Pelotas (UFPel). Caixa Postal 354, 96010-900 Pelotas (RS). E-mail: maraisacrestani@yahoo.com.br (*) Autora correspondente. eamoliterno@gmail.com; gustavodasilveira.faem@gmail.com

$\left({ }^{3}\right)$ Centro de Genômica e Fitomelhoramento - Faculdade de Agronomia "Eliseu Maciel" (FAEM)/Universidade Federal de Pelotas (UFPel). E-mail: carvalho@ufpel.tche.br; acostol@terra.com.br

$\left({ }^{4}\right)$ Departamento de Estudos Agrários/Curso de Agronomia, Universidade Regional do Noroeste do Estado do Rio Grande do Sul (UNIJUÍ), Rua do Comércio, 3000, Bairro Universitário, 9800-000 Ijuí (RS). E-mail: jagsfaem@yahoo.com.br

$\left({ }^{5}\right)$ Departamento de Agronomia da Universidade Federal de Santa Maria (UFSM) - CESNORS, Campus Universitário, Caixa Postal 54, 98400-000 Frederico Westphalen (RS) - E-mail: velciq@gmail.com

$\left({ }^{6}\right)$ Bolsista da CAPES.

$\left({ }^{7}\right)$ Bolsista do CNPq.

$\left({ }^{8}\right)$ Bolsista de Iniciação Científica do CNPq. 


\title{
ABSTRACT \\ ALUMINUM STRESS IN BLACK OAT CULTIVARS UNDER HYDROPONIC CONDITIONS
}

\begin{abstract}
Aluminum content (Al) available in soil solution with high acidity is one of the abiotic factors that strongly intervenes with the growth and development of black oat (Avena strigosa Schreb.). After its assimilation, cells and organelles are affected at morphological, cytogenetic and physiological levels, causing low plant grain yields. In this study, black oat genotypes were subjected to aluminum stress under hydroponic conditions to determine the most effective character for the selection of seedlings in controlled environment. Moreover, other objectives were to characterize distinct genetic compositions of black oats aiming the establishment of crossing blocks; to improve the accuracy of genotype recommendation for environments with high presence of this chemical element, and to establish the aluminum concentration that allows the scoring of aluminum tolerance under hydroponic conditions. Adopting the Camargo and Oliveira, in 1981, methodology, five aluminum levels: 0, 5, 10, 20 and $40 \mathrm{mg}$ $\mathrm{L}^{-1}$, with addition of $\mathrm{Al}_{2}\left(\mathrm{SO}_{4}\right)_{3} \cdot 18 \mathrm{H}_{2} \mathrm{O}$, were used. The experimental design was complete randomized blocks with three replications in $5 \times 10$ factors (dose $\times$ genotype). The character root length and the doses 10 and 20 and $\mathrm{mg} \mathrm{L}^{-1}$ of $\mathrm{Al}^{3+}$ provided the best differentiation between the genotypes regarding aluminum tolerance and sensibility. The black oat cultivar IAPAR 61 evidenced high aluminum sensibility, contrasting with genotypes PRETA COMUM and EMBRAPA 140, which expressed high tolerance in the presence of the toxic element in the culture environment.
\end{abstract}

Key words: Avena strigosa Schreb.; nutrient solution; seedling characters, tolerance; sensibility.

\section{INTRODUÇÃO}

A aveia preta (Avena strigosa Schreb) é uma poacea de grande rusticidade, utilizada como cobertura do solo e/ou para pastejo, e que tem participação importante nos sistemas de cultivo que envolvem tanto a produção direta de grãos, como de leite e carne. Desta forma, tem ocupando extensas áreas nos Estados: Rio Grande do Sul, Santa Catarina, Paraná, São Paulo e Mato Grosso e, atualmente, vem apresentando boa adaptação em outras regiões brasileiras, como no Estado da Bahia (CARDOso JR. et al., 2007).

A aveia (Avena spp.) é uma das principais forrageiras anuais utilizadas na formação de pastagens no período de outono/inverno, cultivada de forma isolada ou consorciada com outras espécies forrageiras de clima temperado, devido à sua alta capacidade de produção de matéria seca, qualidade da forragem, resistência ao pisoteio e baixo custo de produção (MACARI et al., 2006). O cultivo da aveia preta como cultura de cobertura propicia melhorias nas propriedades químicas, físicas e biológicas do solo, auxilia no controle de plantas daninhas e favorece o bom desenvolvimento das culturas comerciais cultivadas em sucessão (SANTI et al., 2003). Esta espécie proporciona alta produção de biomassa, grande capacidade de afilhamento e rebrote, além de possuir sementes menores em relação às outras espécies de aveia, o que diminui consideravelmente os custos de implantação da lavoura (BEvILAQuA et al., 2001).

Muitas vezes, a aveia preta é cultivada em áreas de solos não corrigidos e pouco férteis, com desenvolvimento reduzido em relação ao seu potencial
(SANTI, et al., 2003; Silva e Lemos, 2006). Além disso, de acordo com Wight et al. (2006), um dos fatores abióticos que afetam fortemente o crescimento e desenvolvimento da aveia preta é o teor de alumínio (Al) livre presente na solução dos solos de elevada acidez.

Na composição do solo, o alumínio é considerado o terceiro elemento químico mais freqüente na crosta terrestre, e em situação de $\mathrm{pH}$ abaixo de 5,5, tende a se dissociar das estruturas minerais de argila para a solução do solo, onde geralmente está presente em concentrações na faixa de 10 a $350 \mathrm{mmol} \mathrm{L}^{-1}$ (MACHADO, 1997).

A absorção e o acúmulo de Al pela planta afetam células e organelas em nível morfológico, citogenético e fisiológico, prejudicando consideravelmente o estabelecimento, desenvolvimento e a produtividade final da lavoura (KumAr et al., 1995).

Segundo Fleming e Foy (1968), a tolerância das plantas a este íon metálico está relacionada à capacidade de continuidade da divisão e elongamento celular sob condições de estresse, modificação do ambiente radicular reduzindo a concentração de alumínio disponível, e possibilidade de manter áreas meristemáticas viáveis para a formação de novos tecidos. Portanto, a busca de cultivares melhoradas e tolerantes ao alumínio tóxico representa uma alternativa promissora e sustentável para aumentar a produtividade em solos ácidos, pois as espécies e variedades diferem amplamente nos níveis de sensibilidade ao excesso deste elemento tóxico no solo (WIGHT et al., 2006). 
A reação das plantas ao $\mathrm{Al}$ pode ser detectada e medida com base em distintos caracteres em testes de laboratório em condições hidropônicas, de modo que aferições em plântulas possam estabelecer diferenças que possibilitem separar fenotipicamente as cultivares consideradas tolerantes e sensíveis (CAMARGO e Oliveira, 1981; Camargo, 1998; Ferreira et al., 1999; SANCHES-ChÁcon et al., 2000; Mazzocato et al., 2002; NAVA et al., 2006; Silva et al., 2006; FinatTo et al., 2007).

O presente trabalho teve por objetivo determinar o caráter mais efetivo de seleção em nível de plântula para a detecção de genótipos de aveia preta tolerantes e sensíveis ao $\mathrm{Al}$ em condições de hidroponia, caracterizar distintas constituições genéticas desta espécie visando à composição de blocos de cruzamento, auxiliar na recomendação de genótipos em ambientes com elevada concentração deste elemento químico e estabelecer a concentração de alumínio em solução de cultivo que possibilite maior eficiência na deteç̧ão do nível de tolerância a este íon tóxico.

\section{MATERIAL E MÉTODOS}

No trabalho foram avaliadas cinco cultivares de aveia preta inseridas no Registro Nacional de Cultivares (RNC-MAPA, 2008), que são: AGROZEBU, PRETA COMUM, IAPAR 61, UPFA 21 e EMBRAPA 140, e as linhagens ALFA 94087 e UTG 200075. Pela ausência de informações sobre o desempenho de genótipos de Avena strigosa quanto a reação ao Al tóxico, foram incluídas na avaliação três cultivares de aveia branca (Avena sativa L.), de modo que representem genótipos padrões, já caracterizados quanto à toxicidade ao alumínio em cultivo hidropônico, segundo Finatto et al. (2007) e Silva et al. $(2007 a, b)$ que foram: ALBASUL (sensível), UPFA 22 (tolerância intermediária) e URS 20 (tolerante).

O delineamento experimental adotado foi o completamente casualizado com três repetições, sendo a unidade experimental constituída por dez plântulas, distribuídas em esquema fatorial $5 \times 10$ (dose x genótipo). As sementes dos genótipos foram submetidas à germinação em caixas gerbox com papel germiteste, em BOD à $25^{\circ} \mathrm{C}$ por 72 horas. Posteriormente, sementes uniformes germinadas e com aproximadamente $5 \mathrm{~mm}$ de raiz, foram transferidas para telas acondicionadas sobre recipientes plásticos contendo 1,5 litros de solução completa (ausência de Al), conforme método estabelecido por Camargo e Oliveira (1981), formada pela seguinte concentração dos produtos em $\mu \mathrm{Mol} \mathrm{L}{ }^{-1}$ : $\mathrm{Ca}\left(\mathrm{NO}_{3}\right)_{2}-4000 ; \mathrm{MgSO}_{4}$.
$7 \mathrm{H}_{2} \mathrm{O}$ - 2000; $\mathrm{KNO}_{3}-4000 ;\left(\mathrm{NH}_{4}\right)_{2} \mathrm{SO}_{4}-435$; $\mathrm{KH}_{2} \mathrm{PO}_{4}-500 ; \mathrm{MnSO}_{4} \cdot \mathrm{H}_{2} \mathrm{O}-2 ; \mathrm{CuSO}_{4} \cdot 5 \mathrm{H}_{2} \mathrm{O}-$ 0,$3 ; \mathrm{ZnSO}_{4} \cdot 7 \mathrm{H}_{2} \mathrm{O}-0,8 ; \mathrm{NaCl}-30 ; \mathrm{Fe}-\mathrm{EDTA}-10$; $\mathrm{Na}_{2} \mathrm{MoO}_{4} \cdot 2 \mathrm{H}_{2} \mathrm{O}-0,10 ; \mathrm{H}_{3} \mathrm{BO}_{3}-10$.

Ao completar 48 horas em solução nutritiva completa, as telas com as plântulas foram transferidas para os recipientes de mesmo volume contendo as soluções-tratamento, formadas pela décima parte da solução completa, omitindo o fósforo e adicionando ferro na forma $\mathrm{FeCl}_{3}$, além da inclusão das doses de alumínio, tendo como fonte o $\mathrm{Al}_{2}\left(\mathrm{SO}_{4}\right)_{3} \cdot 18 \mathrm{H}_{2} \mathrm{O}$, na quantidade requerida para atingir as concentrações de $0,5,10,20$ e $40 \mathrm{mg} \mathrm{L}^{-1}$ (equivalente a $0 ; 185,2 ; 370,4 ; 740,8$ e $1.481,6 \mu \mathrm{Mol}$ $\mathrm{L}^{-1}$ de $\mathrm{Al}$ respectivamente).

As plântulas permaneceram 48 horas nesta condição de cultivo. Após este período, as telas com as plântulas retornaram aos recipientes contendo solução nutritiva completa, onde foram mantidas por 72 horas. $\mathrm{O}$ pH das soluções foi corrigido diariamente para 4,0 \pm 0,3, com adição de $\mathrm{HCl}$ e/ou $\mathrm{NaOH} 1 \mathrm{~mol}$ $\mathrm{L}^{-1} \mathrm{e}$ os recipientes mantidos em "banho-maria" (26 $\pm 1{ }^{\circ} \mathrm{C}$ ) em tanque de hidroponia, com aeração constante e fotoperíodo permanente $(1.700 \mathrm{~lx})$.

Aos sete dias de estabelecimento do experimento, foi realizada a avaliação das plântulas pela mensuração, em centímetros, dos caracteres comprimento de raiz (CR), comprimento de parte aérea (CPA), comprimento da primeira folha (CPF), comprimento da segunda folha (CSF), comprimento de coleóptilo (CC), inserção da primeira folha (IPF), número de raízes (NR), em unidade, e matéria seca de raiz (MSR) e de parte aérea (MSPA), em miligramas, após secagem do material vegetal em estufa a $60^{\circ} \mathrm{C}$ até atingir massa constante.

Para atender as pressuposições da análise de variância foi realizada a transformação dos dados por potência ao quadrado dos caracteres comprimento de parte aérea (CPA), comprimento do coleóptilo (CC), inserção da primeira folha (IPF) e comprimento da primeira folha $(\mathrm{CPF})$ e por raiz quadrada do caráter comprimento de segunda folha (CSF).

Os dados foram submetidos à análise de variância com a finalidade de identificar os efeitos simples e da interação, determinando o desempenho relativo para as variáveis que revelaram interação significativa e realizado o ajuste de regressão polinomial para explicar o comportamento dos genótipos em relação aos caracteres que expressaram maiores reações ao Al. Estes procedimentos e as análises foram realizados no programa computacional SAs LeARNing EdiTION (2002). 
Posteriormente, com base nas médias dos caracteres avaliados, utilizando o programa computacional GENES (CRUZ, 2001), estimou-se a distância generalizada de Mahalanobis $\left(D^{2}\right)$ entre todos os pares de genótipos para o comportamento geral dos caracteres em cada concentração de alumínio tóxico adotada, e empregado o método de agrupamento de Tocher, buscando o estabelecimento de grupos de genótipos similares quanto à toxicidade ao Al.

Foi efetuada a identificação da importância relativa de cada caráter para a diferenciação entre os genótipos de aveia, segundo SiNGH (1981), considerando a matriz de distância genética obtida a partir das médias gerais dos caracteres avaliados em cada concentração de alumínio trabalhada. As variáveis que revelaram significância para o fator de tratamento Genótipo foram analisadas pelo procedimento PROC MIXED (LitTELL et al., 1996), através do modelo estatístico REM/BLUP (máxima verossimilhança restrita / melhor preditor linear nãoviesado), descrito por HeNDERSON (1984), utilizando o programa estatístico SAS LEARNING EDITION (2002).

\section{RESULTADOS E DISCUSSÃO}

A análise de variância possibilitou identificar a existência de interação significativa entre os fatores Dose e Genótipo para os caracteres CR, NR, CSF e MSR. Além disso, foram detectadas diferenças para todos os caracteres avaliados em relação ao fator principal Genótipo, bem como para os caracteres CR, NR, CPA, IPF e CC em relação à Dose (Tabela 1). Entre os caracteres que revelaram interação significativa, CR, NR, CSF e MSR, as variáveis CR e NR apresentaram as maiores variações no desempenho relativo da média geral, conforme apresentado na tabela 2 . Desta forma, foi realizado o ajuste das equações de regressão que expressam o comportamento de cada genótipo frente as doses de $\mathrm{Al}$ em relação aos caracteres CR e NR (Figura 1).

Fica evidente que houve modificações nos caracteres de plântula pela adição de $\mathrm{Al}$ na solução de cultivo. Esses resultados iniciais corroboram com a literatura, evidenciando que a ação fitotóxica do alumínio é um fenômeno que afeta tanto o sistema radicular como os caracteres de parte aérea, porém, sua ação é mais visível e efetiva no desenvolvimento das raízes (HARTwig et al., 2007). Este comportamento ocorre devido a alterações nas membranas das células da raiz e inibição da síntese de DNA, levando à paralisação da divisão e elongamento das células, engrossamento e menor ramificação das raízes pela desorganização dos meristemas, além da maior sensibilidade de produção de biomassa radicular, prejudicando, por conseqüência, o desenvolvimento dos tecidos aéreos do vegetal (MACHADO, 1997; TEDESCO e BISSANI, 2004).

De modo geral, analisando a figura 1, é verificado que com o aumento gradativo das doses de $\mathrm{Al}$ na solução nutritiva ocorreu a redução do CR em grande parte dos genótipos de aveia avaliados. Levando em consideração o desempenho individual de cada constituição genética, de acordo com a estimativa do modelo matemático apresentado para CR (equação da regressão), os genótipos AGROZEBU e ALFA 94087 proporcionaram a redução de $0,34 \mathrm{~cm}$ neste caráter a cada $1 \mathrm{mg} \mathrm{L}^{-1}$ de alumínio adicionado, expressando os maiores $\mathrm{CR}$ na concentração mais elevada $\left(40 \mathrm{mg} \mathrm{L}^{-1}\right.$ de $\left.\mathrm{Al}\right)$, como também na ausência do elemento tóxico na solução de cultivo. A adição gradativa do Al no ambiente provocou a queda de $0,29,0,27$ e $0,26 \mathrm{~cm}$ do comprimento de raiz das cultivares PRETA COMUM, EMBRAPA 140 e URS 20, respectivamente, nas quais o CR inicial e final foi de magnitude intermediária a alta. Em relação à cultivar de aveia branca UPFA 22, foi possível visualizar que o comprimento mínimo da raiz foi verificado na concentração de $27,5 \mathrm{mg} \mathrm{L}^{-1}$ de $\mathrm{Al}$ (dose crítica y, sendo $\mathrm{y}=-b / 2 c$ ), e para o genótipo IAPAR 61, este mesmo comportamento foi observado na dose $33 \mathrm{mg}$ $\mathrm{L}^{-1}$, com a diminuição de $\mathrm{CR}$ de 0,83 e $0,94 \mathrm{~cm}$, respectivamente, a cada $1 \mathrm{mg} \mathrm{L}^{-1}$ de alumínio adicionado até atingir a dose crítica.

Na cultivar IAPAR 61, aparentemente, ocorreu aumento do crescimento em menores concentrações de alumínio, cuja presença do íon metálico supostamente estaria levando as plântulas a compensar a presença do elemento tóxico, resultando no maior desenvolvimento do sistema radicular, porém, houve menor $\mathrm{CR}$ em concentrações maiores do elemento químico. As constituições genéticas de ALBASUL, UPFA 21 e UTG 200075 tiveram reduzido desenvolvimento de raiz, tanto na dose zero quanto nas maiores concentrações do Al. Entretanto, não evidenciaram mudança de comportamento em relação à presença do elemento tóxico no ambiente de cultivo, caracterizando estabilidade de desempenho do tipo estática em relação às diferentes situações de ambiente, não variando o CR ao longo do aumento das concentrações do Al na solução nutritiva. Segundo Destro e Montalván (1999), este tipo de estabilidade na prática é pouco explorada, pois, quando presente, geralmente está relacionada a genótipos de pobre desempenho e que não reagem na presença de melhores ambientes. 
Tabela 1. Resumo da análise de variância para os caracteres de plântula: comprimento de raiz - (CR); número de raízes (NR); comprimento de parte aérea (CPA); comprimento de primeira folha (CPF); comprimento de segunda folha (CSF); inserção de primeira folha (IPF); comprimento do coleóptilo (CC); matéria seca de raiz (MSR), e matéria seca de parte aérea (MSPA) em genótipos de aveia submetidos ao estresse por diferentes doses de alumínio em cultivo hidropônico

\begin{tabular}{|c|c|c|c|c|c|c|c|c|c|c|}
\hline \multirow{2}{*}{ Fonte de Variação } & \multirow{2}{*}{ GL } & \multicolumn{9}{|c|}{ Quadrado Médio } \\
\hline & & NR & CR & CPA & CPF & CSF & IPF & $\mathrm{CC}$ & MSR & MSPA \\
\hline & & & & & $\mathrm{Cl}$ & 1 & 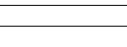 & 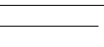 & -1 & 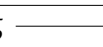 \\
\hline Genótipo(G) & 9 & $6,58^{*}$ & $17,95^{*}$ & $215101,50^{*}$ & $108891,64^{*}$ & $4,86^{*}$ & $198,88^{*}$ & $78,80^{*}$ & $3,21^{*}$ & $79,04^{*}$ \\
\hline Dose (D) & 4 & $0,69^{*}$ & $3,31^{*}$ & $7722,16^{*}$ & $1783,46^{\mathrm{ns}}$ & $0,22^{\text {ns }}$ & $43,98^{*}$ & $2,56^{*}$ & $0,12^{\text {ns }}$ & $6,54^{\mathrm{ns}}$ \\
\hline$G \times D$ & 36 & $0,20^{*}$ & $0,58^{*}$ & $1621,26^{\mathrm{ns}}$ & $918,44^{\mathrm{ns}}$ & $0,10^{*}$ & $3,93^{\mathrm{ns}}$ & $0,65^{\mathrm{ns}}$ & $0,21^{*}$ & $4,68^{\text {ns }}$ \\
\hline Erro & 100 & 0,12 & 0,28 & 2007,90 & 1112,86 & 0,06 & 5,91 & 1,78 & 0,13 & 3,54 \\
\hline Média Geral & - & 3,68 & 4,79 & 18,04 & 14,96 & 1,56 & 3,07 & 2,59 & 1,15 & 6,53 \\
\hline CV (\%) & - & 9,32 & 11,05 & 13,21 & 14,28 & 22,09 & 24,39 & 19,06 & 27,76 & 28,56 \\
\hline
\end{tabular}

GL = Graus de liberdade; CV= Coeficiente de variação; *Significativo a 5\% de probabilidade; ns= Não significativo.

Tabela 2. Desempenho relativo geral dos genótipos de aveia para os caracteres de plântula comprimento de raiz (CR); número de raízes (NR); comprimento de segunda folha (CSF); e matéria seca de raiz (MSR), submetidos ao estresse por doses de alumínio em cultivo hidropônico

\begin{tabular}{|c|c|c|c|c|c|}
\hline Dose de $\mathrm{Al}^{*}$ & Desempenho & NR & CR & CSF & MSR \\
\hline \multicolumn{6}{|l|}{$\mathrm{mg} \mathrm{L}^{-1}$} \\
\hline \multirow[t]{2}{*}{0} & Média geral & 3,84 & 5,00 & 1,09 & 1,15 \\
\hline & Desempenho relativo (\%) & 100,00 & 100,00 & 100,00 & 100,00 \\
\hline \multirow[t]{2}{*}{5} & Média geral & 3,70 & 4,90 & 0,96 & 1,14 \\
\hline & Desempenho relativo (\%) & 96,30 & 98,00 & 88,00 & 99,80 \\
\hline \multirow[t]{2}{*}{10} & Média geral & 3,76 & 4,92 & 1,10 & 1,21 \\
\hline & Desempenho relativo (\%) & 97,90 & 98,30 & 101,00 & 105,40 \\
\hline \multirow[t]{2}{*}{20} & Média geral & 3,61 & 4,58 & 1,18 & 1,26 \\
\hline & Desempenho relativo (\%) & 94,00 & 90,00 & 109,00 & 110,00 \\
\hline \multirow[t]{2}{*}{40} & Média geral & 3,46 & 4,32 & 1,15 & 1,10 \\
\hline & Desempenho relativo (\%) & 90,00 & 86,30 & 105,60 & 95,00 \\
\hline
\end{tabular}

* Concentração de alumínio adicionada em solução hidropônica, tendo como fonte o $\mathrm{Al}_{2}\left(\mathrm{SO}_{4}\right)_{3} \cdot 18 \mathrm{H}_{2} \mathrm{O}$.

Em relação aos genótipos ALBASUL, UPFA 21 e UTG 200075, esta situação é também observada, visto que são altamente estáveis na presença e na ausência do elemento tóxico, em condições hidropônicas; entretanto, evidenciam os menores comprimentos médios de raiz, mesmo na dose zero, confirmando sua inferioridade para este caráter, quando comparados aos demais genótipos avaliados, o que dificulta a recomendação destas constituições genéticas como genótipos promissores em relação à toxicidade por alumínio.

Considerando o caráter $\mathrm{CR}$ e tendo como parâmetros a concentração crítica de Al para cada genótipo, a variação do comprimento de raiz apresentada no intervalo compreendido entre a ausência de alumínio e a dose crítica, assim como o desempenho médio dos genótipos para este caráter, as cultivares UPFA 22 e IAPAR 61 evidenciaram grande sensibilidade ao $\mathrm{Al}$, com as maiores variações de CR no intervalo considerado, bem como as menores doses críticas. Os genótipos PRETA COMUM, EMBRAPA 140 e URS 20 evidenciaram considerável tolerância à presença do $\mathrm{Al}$ no ambiente de cultivo, e o desempenho inicial e final foi intermediário para CR, seguidos dos genótipos AGROZEBU e ALFA 94087. Portanto, as cultivares de aveia preta PRETA COMUM e EMBRAPA 140 e a cultivar de aveia branca URS 20, considerada tolerante, podem ser recomendadas para cruzamentos em programas de melhoramento genético de aveia branca e preta buscando tolerância ao $\mathrm{Al}$, bem como serem adotadas para cultivo em regiões com solos ácidos e de elevada disponibilidade de alumínio tóxico na solução do solo. 

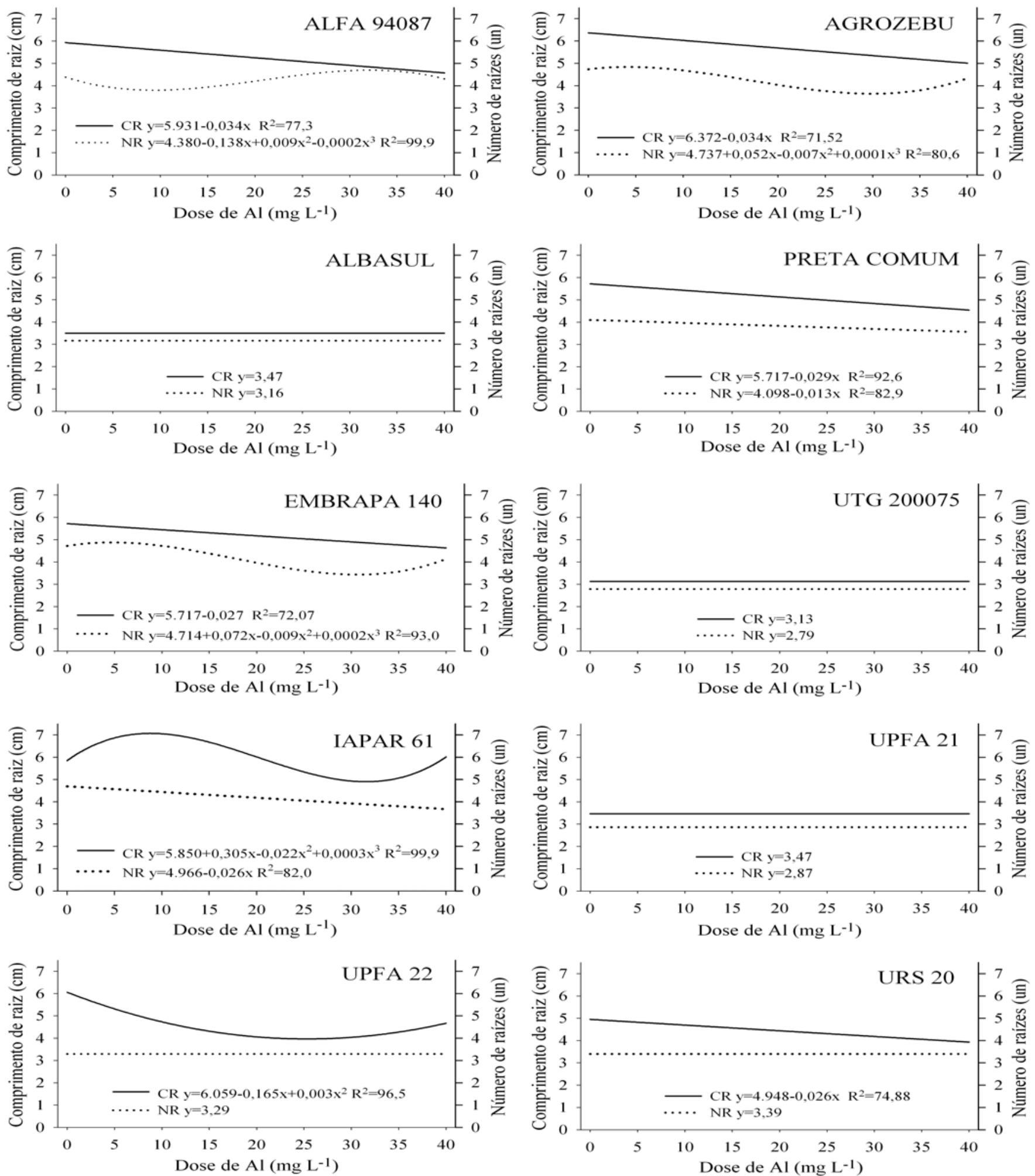

Figura 1. Representação das equações de regressão ajustadas geradas pelo comportamento apresentado pelos genótipos de aveia em relação aos caracteres comprimento de raiz (CR) e número de raízes (NR) avaliados sob estresse por doses de alumínio em solução nutritiva. 
Analisando o caráter NR e considerando os mesmos critérios, verifica-se desempenho similar entre os genótipos, quando comparado ao apresentado em relação ao caráter $C R$. A variável NR, porém, é menos eficiente na caracterização das constituições genéticas quanto à sensibilidade ao Al tóxico, quando comparada ao CR, em virtude da maior instabilidade de comportamento evidenciado, ao longo do aumento das doses, pelas constituições genéticas avaliadas (Figura 1). Desta maneira, entre as variáveis analisadas, o caráter $\mathrm{CR}$ parece ser o mais eficiente em discriminar as cultivares de aveia preta em relação à sensibilidade e tolerância ao $\mathrm{Al}$ nas condições de cultivo hidropônico consideradas. Este fato pode ser justificado pela presença predominante deste elemento químico na região radicular da planta e pela localização do sítio de toxicidade no ápice das raízes (Hartwig et al., 2007). Segundo Machado (1997), o alumínio absorvido paralisa a divisão celular no meristema apical das raízes, resultando em drástica redução do seu crescimento. Portanto, o comprimento da raiz representa um caráter efetivo na avaliação da toxicidade de alumínio e descrição da variabilidade genética entre e dentro de espécies (CAMARGo e
Oliveira, 1981; CAMARgo, 1998; Ferreira et al., 1999; Mazzocato et al., 2002).

Atualmente, o cultivo hidropônico tem sido fortemente utilizado em programas de melhoramento, tendo como grande vantagem a avaliação de genótipos em reduzido período de tempo e em estádio de plântula, empregando caracteres de fácil mensuração e não destrutivos, como o caráter comprimento de raiz, que possibilita o posterior transplante e cultivo das plântulas selecionadas para avanço de geração e futuro teste de progênie (SPehar e MAKITA, 1994).

Objetivando verificar o comportamento dos genótipos de aveia, considerando a análise de todos os caracteres quando submetidos à toxicidade de alumínio, foi efetuada a análise conjunta dos caracteres por meio do emprego do método de agrupamento de Tocher em cada dose do elemento químico, com base na matriz de distância generalizada de Mahalanobis $\left(\mathrm{D}^{2}\right)$, conforme tabela 3. Este método promove um arranjo de modo que exista homogeneidade dentro e heterogeneidade entre grupos formados.

Tabela 3. Agrupamento dos dez genótipos de aveia submetidos a estresse por Al em hidroponia, utilizando-se o método de agrupamento de Tocher, com base na distância generalizada de Mahalanobis $\left(\mathrm{D}^{2}\right)$

\begin{tabular}{|c|c|c|}
\hline Dose de $\mathrm{Al}^{*}$ & Grupos & Genótipos \\
\hline \multicolumn{3}{|l|}{$\mathrm{mg} \mathrm{L}^{-1}$} \\
\hline 0 & $\begin{array}{l}\text { I } \\
\text { II } \\
\text { III } \\
\text { IV }\end{array}$ & $\begin{array}{l}\text { UPFA21, UTG200075 } \\
\text { AGROZEBU, EMBRAPA140, ALFA94087, URS20, UPFA22, ALBASUL } \\
\text { IAPAR61 } \\
\text { PRETA COMUM }\end{array}$ \\
\hline 5 & $\begin{array}{l}\text { I } \\
\text { II } \\
\text { III } \\
\text { IV }\end{array}$ & $\begin{array}{l}\text { AGROZEBU, PRETA COMUM, EMBRAPA140, ALFA94087, IAPAR61 } \\
\text { UPFA21, UTG200075 } \\
\text { UPFA22, ALBASUL } \\
\text { URS20 }\end{array}$ \\
\hline 10 & $\begin{array}{l}\text { I } \\
\text { II } \\
\text { III } \\
\text { IV }\end{array}$ & $\begin{array}{l}\text { AGROZEBU, PRETA COMUM, EMBRAPA140, ALFA94087, UPFA22, URS20 } \\
\text { UPFA21, UTG200075 } \\
\text { ALBASUL } \\
\text { IAPAR61 }\end{array}$ \\
\hline 20 & $\begin{array}{l}\text { I } \\
\text { II } \\
\text { III } \\
\text { IV }\end{array}$ & $\begin{array}{l}\text { AGROZEBU, PRETA COMUM, EMBRAPA140, ALFA94087, URS20, IAPAR61 } \\
\text { UPFA21, UTG200075 } \\
\text { ALBASUL } \\
\text { UPFA22 }\end{array}$ \\
\hline 40 & $\begin{array}{l}\text { I } \\
\text { II } \\
\text { III } \\
\text { IV }\end{array}$ & $\begin{array}{l}\text { AGROZEBU, PRETA COMUM, EMBRAPA140, ALFA94087, URS20, ALBASUL } \\
\text { UPFA21, UTG200075 } \\
\text { IAPAR61 } \\
\text { UPFA22 }\end{array}$ \\
\hline
\end{tabular}

* Concentração de alumínio adicionada em solução hidropônica, tendo como fonte o $\mathrm{Al}_{2}\left(\mathrm{SO}_{4}\right)_{3} \cdot 18 \mathrm{H}_{2} \mathrm{O}$. 
De forma geral, em todas as doses foi verificada a formação de cinco grupos, nos quais havia diferentes constituições nas distintas concentrações de alumínio, com exceção dos genótipos UPFA 21 e UTG 200075, que evidenciaram similaridade genética, compondo um único grupo em todas as concentrações testadas. A cultivar IAPAR 61 merece destaque em relação à formação dos agrupamentos, evidenciando comportamento instável a cada modificação das doses de Al no ambiente de cultivo (Tabela 3 ), também visualizado na análise univariada com base no caráter CR (Figura 1). As cultivares ALBASUL e a UPFA 22 também apresentaram mudanças constantes nas formações dos agrupamentos ao longo das doses, enquanto os genótipos de aveia preta AGROZEBU, ALFA 94087, EMBRAPA 140 e PRETA COMUM constituem os mesmos grupos em todas as concentrações de Al utilizadas.

Observando a classificação dos genótipos com base na análise individual em relação ao desempenho médio para o caráter $\mathrm{CR}$ em cada dose (Figura 1), foi possível notar grande coerência dos agrupamentos formados nas doses de 10 e $20 \mathrm{mg} \mathrm{L}^{-1}$ de $\mathrm{Al}$; sugerindo que essas doses foram as mais efetivas na caracterização dos genótipos de aveia quanto à sensibilidade ao Al tóxico em cultivo hidropônico, considerando inclusive a análise conjunta dos caracteres de plântula. Esses resultados corroboram com outros trabalhos, cujos autores, estudando a sensibilidade à toxicidade de alumínio em aveia branca em solução nutritiva, verificaram que as concentrações de $10 \mathrm{mg} \mathrm{L}^{-1}$ (SILVA et al., 2007a) e 20 $\mathrm{mg} \mathrm{L}^{-1}$ de Al (SANCHES-CHÁcon et al., 2000; SiLVA et al., 2006; FinatTo et al., 2007; SiLva et al., 2007a) foram eficientes na identificação dos genótipos de aveia tolerantes e sensíveis a este elemento tóxico.

Na tabela 4 é apresentada a importância relativa de cada caráter na determinação da distância genética entre os genótipos de aveia e na formação dos agrupamentos em cada concentração de Al avaliada. Nesta análise, observa-se a grande importância dos caracteres de parte aérea (CPA, CPF, CSF e MSPA) na formação dos agrupamentos, tanto na análise geral quanto nas doses 10 e $20 \mathrm{mg}$ $\mathrm{L}^{-1}$ de $\mathrm{Al}$, consideradas, nesta situação de avaliação, as mais efetivas na caracterização dos genótipos quanto à sensibilidade ao alumínio tóxico. Isto demonstra que os danos causados pelo alumínio no sistema radicular refletem indiretamente no desempenho dos caracteres de parte aérea, pois além de interferir no desenvolvimento das raízes, o $\mathrm{Al}$ promove a inibição do desenvolvimento dos demais órgãos e tecidos do vegetal por prejudicar a aquisição e o transporte de água pelas plantas, além de comprometer fortemente a absorção, transporte e utilização de nutrientes (DRUMMOND et al., 2001), devido à competição catiônica do $\mathrm{Al}$ por sítios de troca na raiz, levando ao desbalanço nutricional e comprometimento do desenvolvimento normal das plantas (MACHADO, 1997), o que também é verificado nos caracteres em nível de plântula.

Tabela 4. Contribuição relativa (\%) dos caracteres comprimento de raiz (CR); número de raízes (NR); comprimento de parte aérea (CPA); comprimento de primeira folha (CPF); comprimento de segunda folha (CSF), inserção de primeira folha (IPF), comprimento do coleóptilo (CC), matéria seca de raiz (MSR) e matéria seca de parte aérea (MSPA) na análise de diversidade entre genótipos de aveia submetidos ao estresse por alumínio em cultivo hidropônico, utilizando a distância generalizada de Mahalanobis $\left(\mathrm{D}^{2}\right)$

\begin{tabular}{lcccccc}
\hline \multirow{2}{*}{ Caráter } & \multicolumn{5}{c}{ Dose de Al $^{*}$} \\
\cline { 2 - 7 } & Geral & 0 & 5 & 10 & 20 & 40 \\
\cline { 2 - 6 } CPA & 35,50 & 25,54 & 4,14 & 8,21 & 46,71 & 11,03 \\
MSPA & 23,81 & 11,70 & 6,68 & 11,20 & 5,03 & 40,50 \\
CSF & 14,45 & 18,72 & 4,71 & 12,54 & 4,79 & 6,39 \\
MSR & 8,02 & 5,11 & 17,71 & 11,60 & 1,24 & 1,44 \\
CPF & 7,65 & 19,93 & 3,06 & 16,33 & 26,22 & 9,35 \\
CR & 4,35 & 1,21 & 13,90 & 8,21 & 5,81 & 19,23 \\
IPF & 2,54 & 8,44 & 1,98 & 8,16 & 4,63 & 1,36 \\
CC & 2,51 & 1,55 & 17,18 & 0,28 & 3,37 & 3,48 \\
NR & 1,17 & 7,82 & 30,65 & 13,48 & 2,20 & 7,21 \\
\hline
\end{tabular}

* Concentração de alumínio adicionada em solução hidropônica, tendo como fonte o $\mathrm{Al}_{2}\left(\mathrm{SO}_{4}\right)_{3} \cdot 18 \mathrm{H}_{2} \mathrm{O}$. 

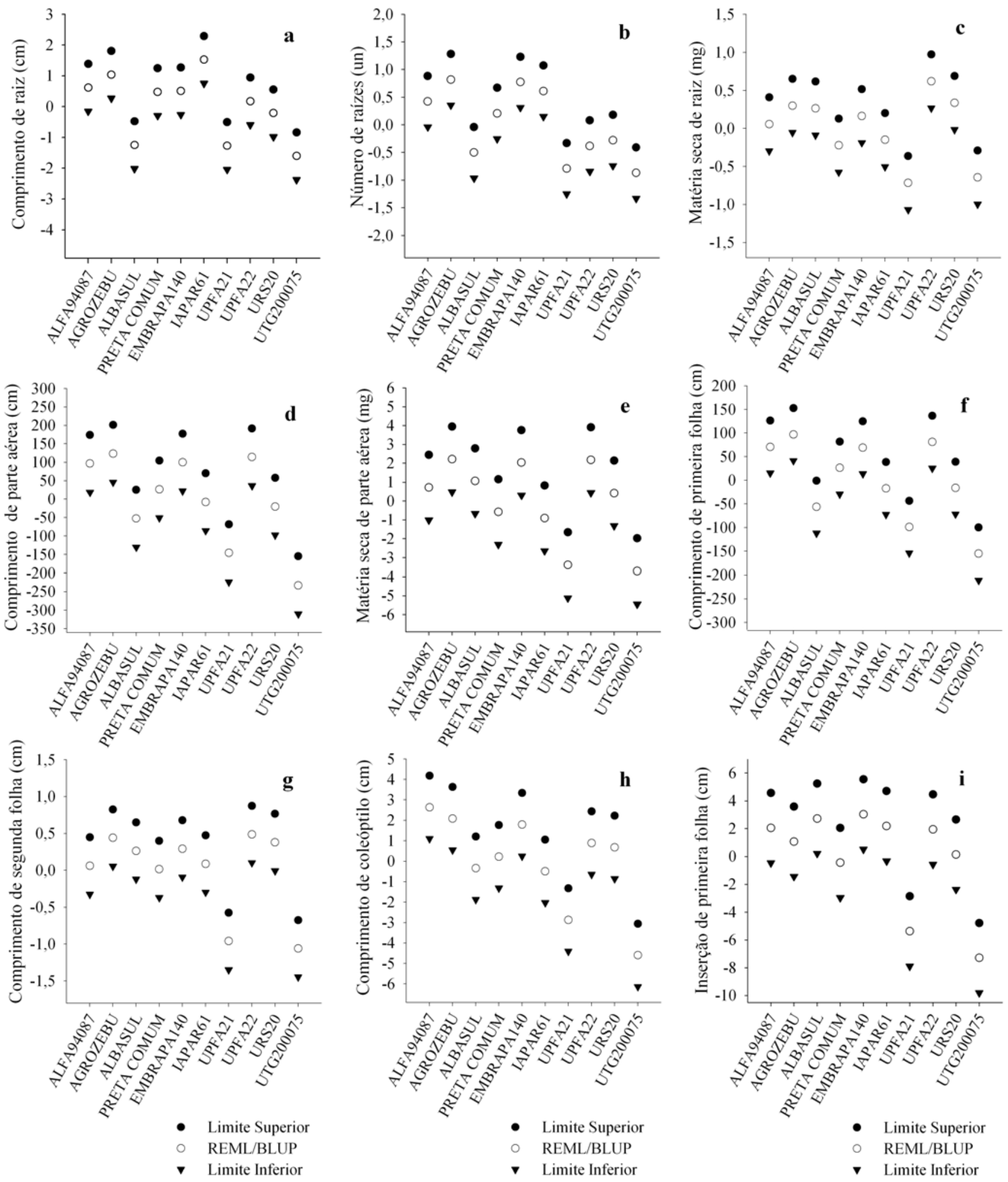

Figura 2. Representação dos valores genéticos (REM/Blup) para os caracteres comprimento de raiz (CR); número de raízes (NR); comprimento de parte aérea (CPA); comprimento de primeira folha (CPF); comprimento de segunda folha (CSF); inserção de primeira folha (IPF); comprimento de coleóptilo (CC); matéria seca de raiz (MSR) e matéria seca de parte aé rea (MSPA) apresentados por genótipos de aveia avaliados sob estresse por alumínio em solução nutritiva. 
Na figura 2, é apresentada a análise do desempenho dos genótipos para os caracteres de plântula avaliados (CR, NR, MSR, CPA, MSPA, CPF, CSF, CC e IPF), na qual são apresentadas as informações relativas exclusivamente aos componentes de variância em relação aos efeitos genotípicos estimados das constituições genéticas trabalhadas (REML/Blup). Os genótipos de aveia preta UFPA 21 e UTG 200075 evidenciaram comportamento inferior para todos os caracteres avaliados, confirmando seu menor potencial genético em relação ao conjunto de genótipos avaliados, acompanhados da cultivar de aveia branca ALBASUL, que se enquadrou na classe de menor desempenho em relação aos os caracteres de raiz CR e NR, e para os caracteres de parte aérea CPA e CPF. Ainda nesta avaliação, ficou evidente a forte relação dos valores genéticos de cada genótipo para o caráter $\mathrm{CR}$ com os demais caracteres de parte aérea, principalmente com CPA e CPF, à exceção do genótipo IAPAR 61, de elevado valor genético para $C R$, ao passo que para $\mathrm{CPA}$ e $\mathrm{CPF}$, os valores foram intermediários a inferiores em relação às demais constituições genéticas. Esse comportamento confirma a relação direta da toxicidade de alumínio sobre o comprimento da raiz e conseqüentes reações expressas nos demais caracteres de parte aérea.

\section{CONCLUSÕES}

1. O comprimento de raiz é o caráter que possibilita, com grande eficiência, a diferenciação entre constituições genéticas de aveia preta quanto à sensibilidade e tolerância ao alumínio em condições de hidroponia.

2. Os genótipos de aveia preta revelaram variabilidade para o caráter sensibilidade e tolerância ao alumínio. A cultivar IAPAR 61, evidenciou grande sensibilidade, enquanto os genótipos PRETA COMUM e EMBRAPA 140 evidenciaram elevada tolerância à presença do elemento tóxico no ambiente de cultivo.

3. As doses de 10 e $20 \mathrm{mg} \mathrm{L}^{-1}$ de $\mathrm{Al}$ em solução nutritiva são eficientes na identificação de genótipos tolerantes e sensíveis ao alumínio tóxico.

\section{REFERÊNCCIAS}

BEVILAQUA, G.A.P.; LINHARES, A.G.; TOMM, G.O. Avaliação e seleção de genótipos de aveia de cobertura de solo para o sul do Brasil. Revista Brasileira de Agrociência, v.7, p.163-169, 2001.

CAMARGO, C.E.O.; OLIVEIRA, O.F. Tolerância de cultivares de trigo a diferentes níveis de alumínio em solução nutritiva e no solo. Bragantia, v.40, p.21-23, 1981.
CAMARGO, C.E.O. Controle genético da tolerância do trigo à toxicidade de alumínio em soluções nutritivas. Bragantia, v.57, p.215-225, 1998.

CARDOSO JÚNIOR, N.S.; VIANA, A.E.S.; OLIVEIRA, J.C.; ANDRADE, J.S.; MOREIRA, E.S.; MUNIZ, W.F.; PEREIRA, G.L. Avaliação da produção de aveia forrageira no estado da Bahia. In: REUNIÃO DA COMISSÃO BRASILEIRA DE PESQUISA DA AVEIA, 27., 2007, Passo Fundo. Resultados experimentais... Passo Fundo: Comissão Brasileira de Pesquisa da Aveia, 2007, v.I, p.126-127.

CRUZ, C.D. Programa Genes - versão Windows 2001.0.0. Viçosa: Editora UFV, 2001. 648p.

DESTRO, D.; MONTALVÁN, R. Melhoramento genético de plantas. Londrina: UEL, 1999, 820p.

DRUMMOND, R.D.; GUIMARÃES, C.T.;FELIX,J.;NINAMANGOCÁRDENAS, F.E; CARNEIRO, N.P.; PAIVA, E.; MENOSSI, M. Prospecting sugarcane genes involved in aluminum tolerance. Genetics and Molecular Biology, v.24, p.221-230, 2001.

FERREIRA, R.P.; CRUZ, C.D.; SEDIYAMA, C.S.; PINHEIRO, B.S. Herança da tolerância à toxidez de alumínio em arroz com base em análise dialélica. Pesquisa Agropecuária Brasileira, v.34, p.615-621, 1999.

FINATTO, T.; SILVA, J.A.G.; CARVALHO, F.I.F.; OLIVEIRA, A.C.; VALÉRIO, I.P.; REIS, C.E.S.; RIBEIRO, G.; SILVEIRA, G.; FONSECA, D.A.R. Reação de tolerância de genótipos de aveia branca a concentrações de alumínio em solução nutritiva. Magistra, v.19, p.07-15, 2007.

FLEMING, A.L.; FOY, C.D. Root structure reflects differential aluminum tolerance in wheat varieties. Agronomy Journal, Madison, v.60, p.172-176, 1968.

HARTWIG, I.; OLIVEIRA, A.C.; CARVALHO, F.I.F.; BERTAN, I.; SILVA, J.A.G.; SCHMIDT, D.A.M.; VALÉRIO, I.P.; MAIA, L.C.; FONSECA, D.N.R.; REIS, C.E.S. Mecanismos associados à tolerância ao alumínio em plantas. Semina Ciências Agrárias, v.28, p.219-228, 2007.

HENDERSON, C.R. Aplications of liner models in animal breeding. Guelph: University of Guelph, 1984. 462p.

KUMAR, P.B.A.N.; DUSHENKOV, V.; MOTTO, H.; RASKIN. I. Phytoextraction: The use of plants to remove heavy metals from soils. Environmental Science and Technology, v.29, p.1232-1238, 1995.

LITTELL, R.C.; MILIKEN, G.A.;STROUP, W.W.; WOLFINGER, R.D. SAS system for mixed models. Cary: SAS Institute Inc, 1996. 633p.

MACARI, S.; ROCHA, M.G.; RESTLE, J.; PILAU, A.; FREITAS, F.K.; NEVES, F.P. Avaliação da mistura de cultivares de aveia preta (Avena strigosa Schreb) com azevém (Lolium multiflorum Lam.) sob pastejo. Ciência Rural, v.36, p.910-915, 2006.

MACHADO, P.L.O.A. Considerações gerais sobre a toxicidade do alumínio nas plantas. Rio de Janeiro: EMBRAPACNPS,1997. 22p. (Documentos, 2) 
MAZZOCATO, A.C.; ROCHA, P.S.G.; SERENO, M.J.C.M.; BOHNEN, H.; GRONGO, V., BARBOSA NETO, J.F. Tolerância ao alumínio em plântulas de milho. Ciência Rural, v.32, p.1924, 2002.

NAVA, I.C.; DELATORRE, C.A.; DUARTE, I.T.L.; PACHECO, M.T.; FEDERIZZI, L.C. Inheritance of aluminum tolerance and its effects on grain yield and grain quality in oats (Avena sativa L.). Euphytica, v.148, p.353-358, 2006.

RNC-MAPA. Registro Nacional de Cultivares do Ministério da Agricultura, Pecuária e Abastecimento. Disponível em: http:/ / www.agricultura.gov.br/images/MAPA/cultivares. Acesso em 9/4/2008.

SÁNCHES-CHACÓN, C.D.; FEDERIZZI, L.C.; MILACH, S.C.K. PACHECO, M.T. Variabilidade genética e herança da tolerância à toxicidade do alumínio em aveia. Pesquisa Agropecuária Brasileira, v.35, p.1798-1808, 2000.

SANTI, A.; AMADO, T.J.C.; ACOSTA, J.A.A. Adubação nitrogenada na aveia preta. I- Influência na produção de matéria seca e ciclagem de nutrientes sob sistema de plantio direto. Revista Brasileira de Ciência do Solo, v.27, p.10751083, 2003.

SAS LEARNING EDITION. Programa SAS - Getting started with the SAS Learning Edition. Cary: SAS Publishing, 2002. 200p.

SINGH, D. The relative importance of characters affecting genetic divergence. Indian Journal of Genetics and Plant Breeding, v.41, p.237-245, 1981.

SILVA, J.A.G.; CARVALHO, F.I.F.; COIMBRA, J.L.M.;BENIN, G.; OLIVEIRA, A.C.O.; VIEIRA, E.A.; FINATTO, T.; BERTAN, I.; SILVA, G.O.; GARCIA, S.M. Tolerância à toxicidade por alumínio em cultivares de aveia (Avena sativa L.) sob cultivo hidropônico. Revista Brasileira de Agrociência, v.12, p.265-271, 2006.

SILVA, J.A.G.; CARVALHO, F.I.F.; COIMBRA, J.L.M.; VIEIRA, E.A.; BENIN, G.; OLIVEIRA, A.C.; FINATTO, T.; BERTAN, I.; SILVA, G.O.; CORREA, M.R. Tolerância ao alumínio em cultivares de aveia branca sob cultivo hidropônico. Bragantia, v.66, p.587-593, 2007a.

SILVA, J.A.G.; CARVALHO, F.I.F.; REIS, C.S.; BERTAN, I.; HARTWIG, I.; MAIA, L.C.; CRESTANI, M.; MARINI, N.; FONSECA, D.A.R.;NORNBERG, R.; LUCHE,H.S.;MOLITERNO, E. Reação de cultivares de aveia (Avena sativa L.) ao estresse por alumínio em condições de hidroponia. In: REUNIÃO DA COMISSÃO BRASILEIRA DE PESQUISA DA AVEIA, 27., 2007, Passo Fundo. Resultados experimentais... Passo Fundo: Comissão Brasileira de Pesquisa da Aveia, 2007b, v.I, p.57-60.

SILVA, T.R.B.; LEMOS, L.B. Produtividade e qualidade fisiológica de sementes de aveia preta em função da calagem superficial em plantio direto. Acta Scientiarum. Agronomy, v.28, , p.207-211, 2006.

SPEHAR, C.R.; MAKITA, M. Tolerância ao alumínio em plântulas de soja e sua utilização. Pesquisa Agropecuária Brasileira, v.29, p.1927-1932, 1994.
TEDESCO, M.J.; BISSANI, C.A. Acidez do solo e seus efeitos nas plantas. In: BISSANI, C.A.; GIANELLO, C.; TEDESCO, M.J.; CAMARGO, F.A.O. Fertilidade dos solos e manejo da adubação de culturas. Porto Alegre: Gênesis, 2004. p.75-92.

WIGHT, C.P.; KIBITE, S.; TINKER, N.A.; MOLNAR, S.J. Identification of molecular markers for aluminium tolerance in diploid oat through comparative mapping and QTL analysis. Theoretical and Applied Genetics, Berlin, v.112, p.222-231, 2006. 